\title{
في منهج التعامل مع التراث
}

\section{*عماد الدين خليل}

قد يكون الإلحاح في التنظير مضللاً في بعض الحلقات المعرفية، وقد ينشئ "تقاليد" تزداد بمرور الوقت شيوعاً، فيجد الباحثون أنفسهم ملزمين بأن يقولوا كلمتهم أو "وجهة نظرهم" في مسألة قد لا تحتاج إلى كبير عناء للتأشير على صيغ التعامل معها.

وهذا ما حدث بالنسبة إلى الموروث المعريز الذي خلفته الأمة الإسلامية عبر التاريخ والذي أصبح للسبب المذكور - حقلاً مفتوحاً لتجارب اليمين والوسط واليسار، إذا صح التعبير، ومورست إزاءه صيغ الانتقاء حيناً، والأحكام (الأيديولوجية) المسبقة حيناً آخر، والتنظيرات الشمولية التي قد ترتطم ببعض حلقاته، حيناً ثالثاً، وكانت النتيجة في كل الأحوال سيلاً من البحوث والمؤلفات التي تنطوي -بالتأكيدعلى كشوف واستنتاجات في غاية الأهمة، ولكنها تتضمن في الوقت نفسه مواقف ومرئيات قد لا تصمد طويلاً بإحالتها على التيار العام للتراث الإسلامي، وخصائصه الأساسية، ومنظومة الأفكار التي تححور حولها

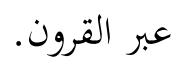

وعلى سبيل المثال فإن تنظير "الجابري" المعررف بخصوص ثلاثية العقيدة والقبيلة والغنيمة التي تفسر

تراث الإسلام، قد لا يكون مقنعاً، وهو يذكرنا بمقولة الكاتب المجري آرثركوستلر من أن الفكرة التي تستطيع تفسير كل شيء، فإها في غاية الأمر لا تكاد تفسر شيئا، كما يذكرنا بتعليق الفيلسوف الإيطالي بنيدتو كروتشه على (مثالية) هيغل من أن فكرة هيغل عن الحياة كانت فلسفية بحيث إن النزعتين المحافظة والثورية بحد فيها ما يبررها. وفي هذه النقطة يتفق انغلز الاشتراكي والمؤرخ المحافظ ترايتشه لأن كليهما يرى أن تماثل المعقول والحقيقي يمكن أن يدعي إليه بصورة متساوية في كل الآراء السياسية والأحزاب التي تختلف عن بعضها، لا من ناحية هذه الصيغة المشتركة، بل في تعيين ما هو المعقول والحقيقي، وما هو غير المعقول وغير 
الحقيقي!!! ومن تَنَّ اتحام خصمه بأنه مخالف للمعقول، أي أنه ليس له وجود ملموس وحقيقي، ويكون هذا الادعاء قد وضع نفسه مع الفلسفة في خط واحد!!! 1

إن الوقائع التاريخية --إذا أردنا الحق - تستعصي على القياس، وتتأبى على المسطرة، ولقد مارس الكثيرون هذا الأسلوب فأخفقوا، لأن منظوماتم المهندسة باتقان اخترقت في أكثر من مكان، وليست تنظيرات الماركسية عنا ببعيدة. إننا نتذكر هنا -أيضاً- استتناجاً لالكسيس كاريل في "الإنسان ذلك الجهول" بخصوص طرائق عمل الدماغ البشري يشير فيه إلى عشق العقل البشري هندسة الظواهر والأشياء وترتيبها في أنساق محددة، حتى لو كانت ظواهر حيوية يصعب إخضاعها للنظام بخلاف الظاهرات الفيزيائية

لننظر -على سبيل المثال- في تاريخ أوروبا في العصور الوسطى، فماذا نجد؟ إن العقيدة والغنيمة والقبيلة هي المؤثرات الأساسية في هذا التاريخ. ولو رجعنا إلى ما قبل هذا التاريخ، أو إلى تاريخ أية أمة من الأمم فإنا سنجد هذا المثلث -إلى جانب مؤثرات أخرى- يلعب دوره المؤكد في الصيورة التاريخية لتلك الأمة. هذا هو قدر التاريخ البشري، فإذا حاولنا أن نقصر الظاهرة على أمة بالذات وقعنا في الخطأ بل إنه حتى التاريخ الحديث والمعاصر يشهد على فاعلية هذه العوامل الثلاثة: أليس الاستعمار والبحث عن مناطق النفوذ في العالم محاولات غنائمية؟ أليس التمبيز العنصري في أمريكا مزاجاً قبلياً بشكل من الأشكال؟ أليس الصراع بين الكنيستين الكاثوليكية والأرثوذكسية صراعاً عقدياً؟ والاستعمار نفسه ألا يمكن أن نضيف إلى بعده الغنائمي بعداً عقدياً (صليبيا) وبعداً قبلياً يتحرك تحت غطاء تفوق الرجل الأبيض؟ لا بل إن التجربتين النازية في المانيا والفاشية في إيطاليا تنطويان -بشكل أو بآخر - على ثلاثية العقيدة والغنيمة والقبيلة؟ إذن ما الذي نسمي الصليب المعقوف والممارسات الإيطالية الصليبية في ليبيا والبحث عن المجال الحيوي وسط أوربا ودعوى الآرية والرومانية في التجربتين؟

$$
\begin{aligned}
& 1 \text { ا } 1 \text { عبد الحميد صديقي: تفسير التاريخ، ترجمة كاظم الجوادي، الدار الكويتية للطباعة والنشر، ص76-77-77. } \\
& 2
\end{aligned}
$$


هذا مثال على السياق العام في التعامل مع التراث. وهناك بين يدي مثال آخر على السياق الخاص متمثلاً بمحاولة إرغام حلقة ما من التراث، أو مفكر أو مؤرخ أو فيلسوف، على أن ينطق بلسان عقائدي القرن العشرين.

يقول مهدي العامل في كتاب يحمل عنوان "في علمية الفكر الخلدوني": "ثورة ابن خلدون الفكرية تكمن، في أنه حرر الفكر التاريخي من هيمنة الفكر الديني، بأن اكتشف في واقعات التاريخ عقلها المادي فأحلّ ضرورة العمران محل الله - أو ما يشبهه - في تفسير الظاهرات جميعاً فاستبدل التأويل بالتفسير، فكأن التفسير، بالضرورة، مادياً، وكان علمياً من حيث هو مادي، دون أن يعني هذا رفضاً للدين، أو الشرع، ومبادئه. فالشرع شيء، والتاريخ - أو العمران - شيء آخر، وليس هذا ذلك ولا ذاك هذا! وإذا دخل الشرع، أو الدين، في حقل العمران، أو التاريخ، كما هو واقع الأمر في "المقدمة"، فكأمر عمراني، أو تاريخي، مادي، لا كأمر غبيي أو إلهي، وينظر فيه، حينئ، بعين العمران وقوانينه، لا بعين الدين ومبادئه، أو بعين الشرع وأحكامه. فلمسائل الشرع منطقها، ولمسائل العمران والتاريخ منطقها، ولا يصحّ، في المعرفة، الخلط

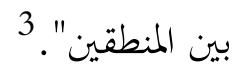

وغير هذين المثالين تيار من الشواهد يمكن أن يضع المرء يده عليها وهو يتابع البحوث والمؤلفات التي شهدما المكتبة العربية عبر ربع القرن الأخير بخصوص منهج التعامل مع التراث، ولن يتسع المجال في صفحات محدودة لإيراد المزيد منها. في ضوء هذا كله لابد من التأثير على جملة من الضوابط والمعايير الأساسية في منهج التعامل مع التراث، إذا أردنا - فعلاً - أن نصل إلى صيغ واستنتاجات أكثر دقة وأدعى إلى القبول:

أولاً: إن هذا التراث هو تراث إسلامي على وجه التحديد، يعكس بدرجة أو أخرى - تصوراً متميزاً للكون والعالم والوجود، وأنه - بشكل أو بآخر - تعبير عن العقيدة والشريعة الإسلاميتين، بغض النظر عن مدى توافق هذا التعبير أو تغايره - أحياناً - مع ثوابت هذه العقيدة أوالشريعة. 3 3 دار الفارابي، بيروت - 1986م، الطبعة الثانية (ينظر تعليق الناشر على الغلاف الخلفي للكتاب). 
لقد هيأت العقيدة الإسلامية، عن طريق المعطيات القرآنية والنبوية المناخ المناسب للنشاط المعريف، ومنحته الحوافز والمبررات، ودفعته إلى العطاء، ومكنته من مجاهة تحديات المعارف التي وجد المسلمون أنفسهم قبالتها في أعقاب عمليات الفتح الكبرى، والتي كان عليهم أن يؤصلوا شخصيتهم الثقافية إزاءها، ليس عن طريق الانغلاق على الذات الذي قد يقود إلى الاضمحلال والانكماش، وليس عن طريق تقبل هذه المعارف بالكلية، الأمر الذي قد يقود إلى الادّغام في الآخر، وإنما باختيار الحل الوسط الذي يقوم على الانفتاح والتحصن.. القبول والرفض.. الأخذ والعطاء.

وقد يكون الحديث عن دور الإسلام، عقيدة ومنهجاً وتشريعاً، في تشكيل المناخ المعريف، مسألة عقدية صرفة، ولكننا سرعان ما ندرك بعدها التاريخي بمجرد أن نتذكر ما تمخض عنها من نشاط معرفي عبر تاريخنا الإسلامي، والخصائص التي اكتسبها هذا النشاط وهو ينبثق عن العقيدة التي صاغت، أو أثرت بمفرداته على أقل تقدير، وبمجرد أن نتذكر أن هذا الدور أحدث تغييراً أساسياً في المواريث الفكرية (الوضعية والدينية المحرفة) التي كانت سائدة في العالم على عهد ظهور الإسلام، وبمجرد أن نقارن المدى الواسع للنقلات المعرفية التي حققها الإسلام والتي لم يبلغ العقل البشري الوضعي حافتها إلا بعد انقضاء قرون طويلة.

إننا بمجرد أن نتذكر هذا كله، نتبين كيف أن الدور الذي رسمه ونفذه الاسلام في السياق المعرين، كان - بمعنى من المعاني- دوراً تاريخياً، أي ممارسة في صميم الحركة التاريخية التي استمرت تتصادى في فاعليتها مع مقوماتا الاسلامية عبر العصور التالية كافة، ومن ثم صاغت معرفة متميزة كان لها ثقلها وخصوصيتها و تأثيرها بين ثقافات التاريخ البشري كله.

إن انعكاس المبادئ الإسلامية الأساسية على النشاط المعريف عبر تاريخنا منحه خصائصه الإسلامية المتميزة التي يمك أن تمثل ليس مبرر استمراره في العالم فحسب، بل تمنحه القدرة على اقتحام شبكة النشاط المعريز للحضارة الراهنة، والقدرة الفعالة على الاسهام المستقبلي فيه. 
ولن يتسع المجال للتأشير على بعض ما قاله الباحثون الغربيون لتأكيد هذا الانعكاس، ويكفي أن نحيل القارئ إلى بعض شواهده...4 وهذا التأكيد يعد -ولا ريب- ضرورة علمية بسبب صعوبة الفصل بين النشاط المعريف الإسلامي عبر التاريخ، والبيئة الإسلامية التي تشكل فيه وتلقى عنها مؤثراته وحوافزه ومكوناته. وما من ريب - استناداً - إلى هذا - في أن أية محاولة لتوهم فصل أو تعارض كهذا، إنما هي أسلوب مضلل في دراسة تراثنا المعريف، ولن تكون نتيجته سوى حشود من الأوهام والأخطاء التي تنافي روح البحث العلمي الجلاد.

ثانياً: وهذا لا يعني - بالضرورة - إدراج النصوص القرآنية والنبوية التي تنبني عليها العقيدة والشريعة، إن في سياق المعطى التراثي، بسبب من اختلاف المصدرين، والخصائص المتميزة لكل معطى. فنحن في الحالة الأولى نجد أنفسنا قبالة موروث ينطوي على الصواب والخطأ، لأنه موروث بشري، أو وضعي، بالمفهوم اللغوي. على حين تعكس الحالة الثانية معطيات إلهية ونبوية "يقينية" لا تقبل أيما نقص أو خطأ. وهكذا فإن المسلم ها هنا يجد نفسه ملزماً بالأخذ، بالقبول والتسليم، أما هناك فهو بازاء هامش واسع من الحرية والاختيار في الأخذ والرد والتغيير والتحوير.

وإذا كان التراث بمفهومه الوضعي وليد لحظة زمنية ما، أو بيئة محددة أغلب الأحيان، فإنه يظل - إلى حد كبير - مشروطاً بالتاريخ والجغرافيا... قد يتحرر منهما - بكل تأكيد - في هذه الناحية، أو تلك، وعبر

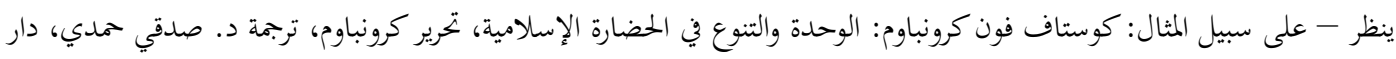

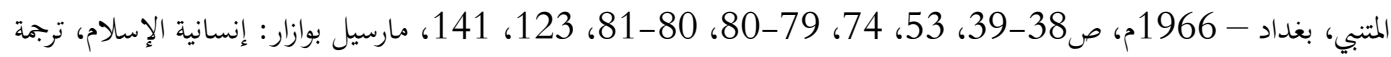

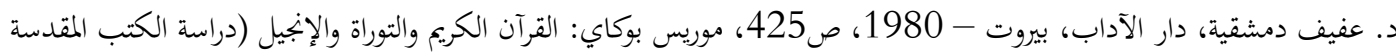

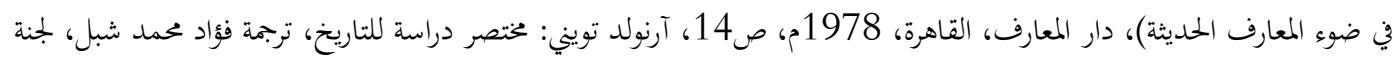

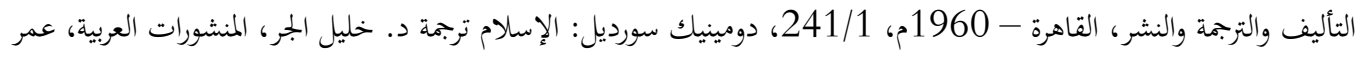

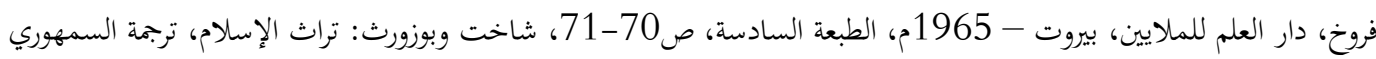

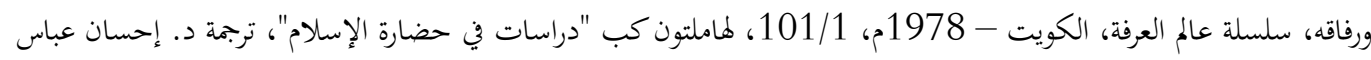

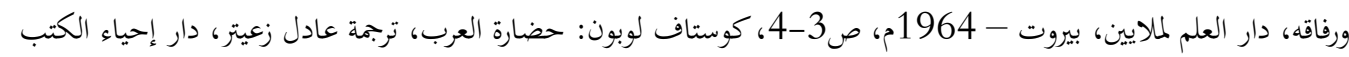

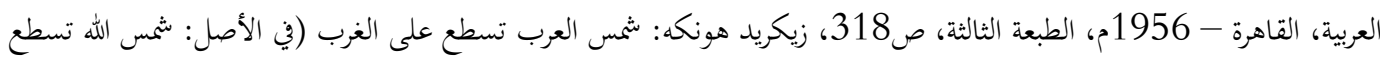

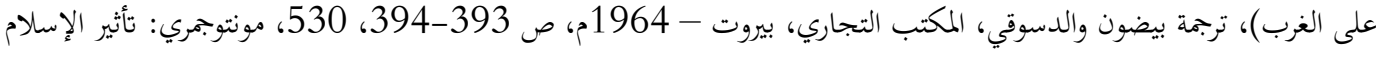

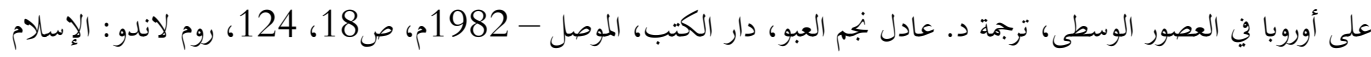

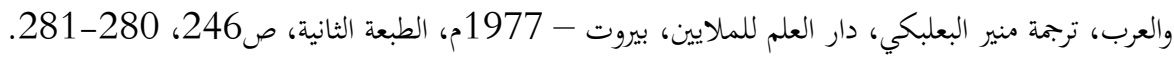


هذا المسار أو ذاك، لكنه في الأعم الأغلب يبقى انعكاساً لوضع نسبي يصعب سحبه على كل الأماكن والأزمان. في حين نجد أنفسنا ونحن نتعامل مع القرآن والسنة، أننا في التاريخ وخارجه، في التراث وبعيداً عنه... إفما يتعاملان بكل تأكيد مع التاريخ والجغرافيا، بحكم التوجه الواقعي لهذا الدين، الذي يستهدف إعادة صياغة الحياة في الزمن والمكان في ضوء معايير ومعطيات الوحي القادمة من فوق. ولكن هذا ليس هاية المطاف، وإلا وقع التعارض - ابتداء - بين المنطوق الدين للإسلام والمنطوق الوضعي الذي يراد أن يصب فيه أو يؤثر في حدوده.

إن النص الديني يتحرر من الجغرافيا والتاريخ، ويتجاوز مواضعات الزمان والمكان، ويمضي لكي يتعامل مع كل لحظة، أو بيئة، وفق مطالبها المتميزة، قديراً على الحضور بكل ثقله في قرن عاشر أو عشرين، في ساحة إفريقية أو آسيوية أو أمريكية، ومن ثم فإن محاولة إرغامه على أن يصير معطى تراثياً إنما هي محاولة خاطئة ومضللة ابتداء. إن تراث أمتنا ليس الاسلام والاسلام ليس تراث أمتنا بالشكل الرياضي الصارم كتطابق مثلثين تناظرت زواياهما. إنما يجيء التراث نتاج تفاعل، بالإيجاب والسلب، مع الإسلام بالدرجة الأولى، ومع عدد آخر من المذاهب والثقافات والأديان، بدرجة أو أخرى، فهو إذن - التراث - حشد من المعطيات تتمخض عن طبيعة التجربة التي أحدثتها مواقف آبائنا وأجدادنا في تعاملها مع هذا الدين ومع حيثيات التاريخ والجغرافيا ونسبيتهما.

إن الاسلام عقيدة ومنهاج صاغتهما يد الله الحكيمة القديرة المريدة العالمة ومنحتهما الصفة الدائمة التي تتجاوز حدود الزمن والمكان وأطروحتهما الموقوتة الزائلة المتغيرة النسبية، لكي تكون بمثابة استشراف كامل، مرن، يتسع لكل حالة، ويحتوي كل تجربة بغض النظر عن موقعها في الزمان والمكان.

أما التراث فهو عطاء موقوت، وهو رغم تأثيراته الدائمة الممتدة في مسارب الزمان والمكان، لن يبلغ حالة الاستمرارية والدوام، كما أنه - بوصفه حصيلة لقاء واقعي بين الإنسان والعقيدة - يجيء متأرجحاً بين الفجاجة والنضج، وبين الصرامة والمرونة، وبين النقص والكمال. 
ثالثاً: وهذا يقود إلى معيار أو حقيقة أخرى: إن تراث المسلمين الذي يعكس الحالة الاسلامية، وينطوي في الوقت نفسه على احتمالات الخطأ والصواب.. الرؤية النسبية والتصور الممتد في الزمن والمكان... هذا التراث، بعد فلك الارتباط بين معطياته وبين النصوص الدينية المستمدة من الوحي، لا يحمل - بالضرورة حكماً ملزماً بقبوله، أو التعامل معه بأي قدر من الإجلال والتقديس، ومن ثم ينفتح المجال للأخذ والرد، للقبول والرفض، ولانتقاء المنضبط بمعايير مستمدة من داخل الحالة الاسلامية لا من خارجها، من أجل أن نكون صادقين مع أنفسنا وتراثنا.

بمعنى أن استدعاء معايير خارجية قد لا يكون على المستوى المنهجي، عملاً صحيحاً، لأنه سيقود إلى نتائج خاطئة أو مضللة، فيما يذكرنا بالخطأ الحسابي الذي يجعل من حاصل جمع برتقالة وتفاحة: اثنتين. وهذا هو الذي حدث ويحدث عبر الزمن الراهن، ومن خلال سيل من البحوث والدراسات التي أرادت إرغام هذا التراث على الخضوع لمعايير "أجنبية" بمعنى الكلمة، وجعل منظومة الأفكار المتشكلة عبر القرنين الأخيرين حاكماً على التراث المتشكل في قرون سبقتها بعمق زمني كبير.

ولأضرب مثلاً واحداً فحسب على هذه الخطيئة التي تغطي مساحات واسعة من أعمال المعاصرين،

$$
\text { شرقيين كانوا أم غربين. }
$$

يذكر المستشرق الهولندي دي بوير "بأن الدين لم يؤثر في آراء - ابن خلدون - العلمية - في المقدمة

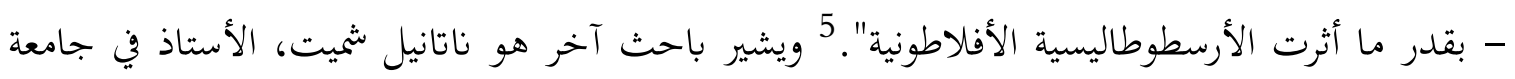
كورنال بأمريكا إلى أن ابن خلدون "إذا كان يذكر خلال بحثه كثيراً من آيات القرآن، فليس لذكرها علاقة جوهرية بتدليله، ولعله يذكرها - فقط - ليحمل قارئه على الاعتقاد بأنه في بحثه متفق مع نصوص القرآن". 6 وثمة مستشرق ألماني هو فون فيسندنك يقول إن ابن خلدون "تحر من أصفاد التقاليد الإسلامية في درس

5 5 5 ممد عبد الله عنان: ابن خلدون: حياته وتراثه الفكري، مطبعة لجنة التأليف والتزجمة والنشر، القاهرة - 1965م، الطبعة الثالثة،

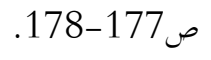
6 
شؤون الدولة والادارة وغيرها، وأنه حرر ذهنه - كذلك - من القيود الفكرية التي ارتبطت في عصره بالعقائد العربية الصحيحة".

ويبقى أن التراث ليس معطى مقدساً، أو وقراً تنوء به ظهور أجيال المسلمين على مدار القرون، فإن القرآن الكريم نفسه إذ وضعنا في مساحات واسعة منه تربو على النصف، في التاريخ، حررنا منه في الوقت

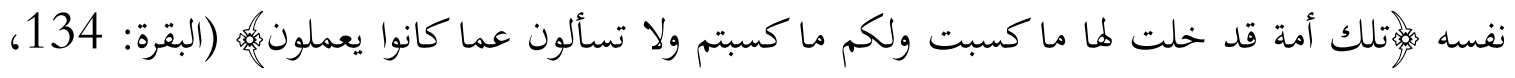
141)، ،هإنا وجدنا آباءنا على أمة وإنا على آثارهم مقتدون (الزخرف: 23). وهذا يقودنا إلى مسألة منهجية أخرى:

رابعاً: إذ ما دام الأمر كذلك فإن لنا، ونحن نطمح للتأصيل الإسلامي للنشاط المعرين، ولصياغة مشروعنا الحضاري، أو وضع لمساته الأولى بشكل أدق، أن نرسم منهجاً مناسباً ومرناً في التعامل مع التراث، منهجاً يمنح المشروع عمقه التراثي، وشخصيته وخصوصياته، ولكنه يحرره في الوقت نفسه من تيار من المعطيات قد لا تكون مناسبة أو ضرورية لحملها والمضي بها قدماً عبر القرن الجديد. أولاً: لكوغا أسيرة لحظة ما من التاريخ أو بيئة ما من الجغرافيا، قد تكون صالحة "هناك" ولكنها لا تحمل جواز مرورها إلى لحظات أو بيئات أخرى. ثانياً: لكوها تنطوي على استنتاجات متناقضة، أو خاطئة ابتداءً، بالإحالة على الكشوف المعرفية الاكثر حداثة. ثالثاً: لكوها تقف عائقاً أمام حرية الفقيه في تنزيل أحكامه على الواقع المتغير في ضوء مقاصد الشريعة العليا، ووفق الضوابط الأصولية المتعارف عليها.

إن الامام الشافعي نفسه (رحمه الله) أفتى بكصر في قضية ما بغير ما أفتى به فن العراق إزاء القضية نفسها. أي أنه - بمعنى من المعاني - لم يحمل معه وهو يرحل إلى مصر مطالب البيئة العراقية، ووجد نفسه حراً في إصدار "قضاء" جديد. وهذا ينسحب على تغاير الأزمان مثلما هو بالنسبة إلى تغاير الأماكن. خامساً: وفي ضوء هذا كله يمكن إعادة تفكيك الموروث المعرفي الاسلامي، أو محاولة تصنيفه وفق أولويات وضوابط محددة تستهدف التأشير المتأني على ما يلي: 
1- المساحات التراثية "المرحلية" التي فقدت قدرتا على المرور إلى العصر والتي يمكن أن تكون مجالاً للتحقيق والبحث والدراسة في السياقات العلمية والأكاديمية والتاريخية.

2- المساحات "الحيوية" المرنة والقديرة على الاستمرار، والتي يمكن أن تضيف إلى المعرفة البشرية الراهنة والمستقبلية رصيداً خصباً من المعطيات في هذا الفرع المعرفي أو ذاك.

3- المساحات التي تعكس التأثير العقدي الاسلامي، ومنطلقه الأساس، ومحوره الأم: التوحيد، بأكبر

$$
\text { قدر من الصدق والفاعلية. }
$$

وهكذا، فإن النشاط المعريف عبر التاريخ الاسلامي لن يتجاوز توجهات ثلاث. أما أوها فهو يغطي المساحة الواسعة في نسيج هذا التراث، وهو ذو دوافع ومعطيات ونتائج إسلامية. وهذا أمر طبيعي لأن الأرضية التي يقوم عليها هذا النشاط، والبيئة التي يعمل فيها، إسلامية التكوين في جل سياقاتا.

والتوجه الثاني الذي تضيق به المساحة يتضمن معارف محايدة لا تحتوي أيما قدر من التأثير الإسلامي

$$
\text { (كما هو الحال مثلاً في بعض العلوم المنقولة عن الآخرين). }
$$

أما التوجه الثالث، الأضيق نطاقاً، فيتضمن أنشطة معرفية مضادة للإسلام (من مثل ما نجده في

$$
\text { أدبيات الشعوبية والمعطيات الفكرية لحركة الزندقة). }
$$

ويبقى التوجه الأول ذو الصبغة الاسلامية، هو التوجه الأكثر امتداداً والأعمق تعبيراً عن عمل العقل المسلم. فإذا أردنا أن نختبر مصداقية هذه المقولة فإن لنا أن نتذكر أنماط المعارف التي تشكلت في دائرة العلوم الإسلامية، تلك الأنماط التي يتضمن كل منها حشوداً من الكشوف والمصنفات، ومئات وربما ألوفاً من البحوث التي تعرض وتوثق وتحلل وتستنتج... إلخ فهناك:

أولاً: معرفة تعالج قضايا إسلامية (علوم القرآن والحديث، والفقه والتشريع). ثانياً: معرفة تحادل عن قضايا إسلامية (علم الكلام، الفلسفة، الأدب...). ثالثاً: معرفة منبثقة عن قضايا إسلامية (التاريخ، علوم اللغة، البلاغة...). 


$$
\text { سابعاً: معرفة متشكلة لحل قضايا إسلامية (الحساب، الطب...). }
$$

سابعاً: معرفة تستهدف تنفيذ مطالب الحياة الاسلامية (علوم الإدارة السياسة، التربية...).

ثامناً: معرفة تحلل ملامح الحياة الإسلامية (علم النفس، الاجتماع...).

تاسعاً: معرفة تحكي وتوثق للحياة الاسلامية (التاريخ، الأدب، الجغرافيا).

عاشراً: معرفة تؤكد قيم الحياة الاسلامية وتدعو لها (الأخلاق، الرقائق).

فإذا انتقلنا للتأشير على بعض العلوم والمعطيات التي تمخضت عن النشاط المعريف في التاريخ الاسلامي لتحديد طبيعة التأثيرات الاسلامية في نسيجها، فإننا سنجد هذا التأثير يمتد إلى كل علم وفن فلا يكاد واحد منها يند عن دائرته بالمفهوم الرؤيوي الشامل، بل إننا سنجد بعضها يتشكل في رحم البيئة والمؤثرات الإسلامية، وبعضها الآخر سيصوغ مناهجه في العمل من مفردات هذه البيئة، وفئة ثالثة ستضيف خبرات جديدة في الحقل الذي تعمل فيه، وستكون هذه الخبرات إسلامية في دوافعها وتكوينها وأهدافها.

ويصعب على المرء في حيز كهذا أن يتابع العلوم والآداب كلها، أو أن يؤشر عليها، كما يصعب عليه أن يضرب مثلاً على ما قدمه كل منها من أعمال وكشوف ومصنفات، ولعل نظرة متأنية في فهارس التراث الإسلامي (كتلك التي أنجزها ابن النديم وحاجي خليفة أوبروكلمان وفؤاد سيزكين) تعوض بعض الشيء عن الدخول في التفاصيل. ومن ثم نكتفي هنا بمجرد التأشير الذي تحتمه ضرورات الإيجاز.

فعلم التاريخ -مثلا- يتجذر في أساسه في المنهج الإسلامي حيث يستعير من مناهج المحدثين في علم الرجال والجرح والتعديل، ومن متابعة الحياة التي تحرك في مساربها رواة الحديث، طرائقه في العمل، وهو يطرح، على أيدي مؤرخين كالطبري والدينوري واليعقوبي والمسعودي، رؤية عالمية للتاريخ البشري تستمد مقوماتحا من المنظور الإسلامي الذي يعاين التاريخ من خلال توالي الرسالات السماوية ذات الأصول المشتركة والهدف رد رد 
الواحد، وصولاً إلى الإسلام خاتم الرسالات، والأمة التي حملت أمانته الصعبة. فإذا تذكرنا الآفاق الضبقة (القبلية والبيئة) التي كانت تحكم العقل العربي، وجل الأقوام الأولى قبل الإسلام، عرفنا كيف كانت التاثيرات الإسلامية قديرة على كسر الجدران وفتح الآفاق باتحاه العالمية وِمن تََّّ تويل التاريخ من حكايات وأيام ووقائع وأخبار مارستها هذه القبيلة أو تلك إلى عرض للتاريخ البشري كله.

ثم إن علم التاريخ مضى قدماً على أيدي أبنائه المسلمين لكي يقدم للفكر، التاريخي إضافات ذات غناء كبير على مستوى المنهج والموضوع. وبنظرة سريعة على رفوف مكتبتنا التاريخية ما بين تواريخ عامة تعتمد منهجاً حولياً أو موضوعياً، وتواريخ محلية تتابع معطيات مدينة ما أو إقليم أو كيان سياسي، وتتوغل في نسيجه الحضاري دون الاكتفاء بالوقوف عند سطح الأحداث السياسية - العسكرية. ومؤلفات في الخطط تتابع جغرافية المدن وتضع لمساتا الإسلامية على خرائطها. كما أننا نجد سيلاً من كتب التراجم التي تغطي المساحة الواسعة في المكتبة الإسلامية التاريخية، التي يتفرد بها تاريخ الأمة الإسلامية، كمّاً ونوعاً وقياساً على تواريخ سائر الأمم والحضارات الأخرى. فإذا تذكرنا الارتباط الصميم بين هذا النمط التاريخي وعلوم الحديث، عرفنا كيف تكون التراجم وليداً شرعياً للبيئة الإسلامية. وبمقدور المرء أن يتابع ألوف المصنفات في هذا السياق، وهي بدورها تنطوي على تغاير في صيغ العرض، فبعضها يعتمد التسلسل الأبجدي وبعضها الآخر الحد الزمني أو المكاني، وفئة ثالثة تتابع التخصص العلمي للمترجم لهم، ورابعة تكتفي بالوقوف عند الرجال الذين أتيح لهم أن يكونوا في قمة الهرم الاجتماعي أو السياسي، وخامسة، وهي الأكثر عطاء، تحكي لنا عن أولئك الذين أغنوا الحياة الإسلامية بأعمالمه، وضربوا مثلاً عملياً بسلوكهم الخاص، على ما يريده هذا الدين من أبنائه. ولم يكن معظم هؤلاء سوى أناس عاديين من قلب المجتمع، بل من قاعه، إذا تابعنا مقاييس

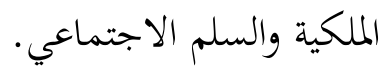

ولم تقف حركة علم التاريخ في الإسلام عند حد، إلا لتتجاوزه إلى آفاق جديدة، إذ إننا ما نلبث أن نجد مؤرخين يرفضون اعتبار التاريخ مجرد أداة سردية للوقائع التاريخية تكتفي بالعرض والوصف، وإنما هي مع هذا بل قبل هذا، منهج للتفسير والتحليل، وإذا بنا نلتقي مع رجال كالطرطوشي والماوردي وابن خلدون، 
بالتاريخ وهو يوشك أن يماذي علم الاجتماع لأول مرة، ويسعى إلى تفسير الظواهر الاجتماعية مستمداً مادته ومنهجه من البيئة والمؤثرات الإسلامية الأصيلة.

والجغرافيا تمد جذورها هي الأخرى في الحياة الإسلامية وصفاً لهذه الحياة، واستجابة لتحدياتا، واستمداداً من المنظور لمفهوم الرحلة بوصفها مفردة إسلامية كان هذا الدين قد عدها فرصة للثقرب إلى الله.

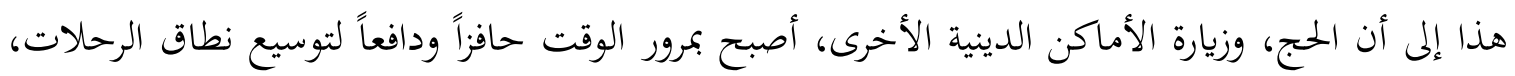
وتزايد البلدانيين عدداً وعطاء، ونقرأ رحلات (ابن جبير) و(ابن بطوطة) و(الهروي) فنرى كيف كان نداء الموقع الديني يدفعهم إلى الرحيل، فضلاً عن تشوقهم المعريخ ورغبتهم الأكيدة في تنمية خبراتم بالمشاهدة

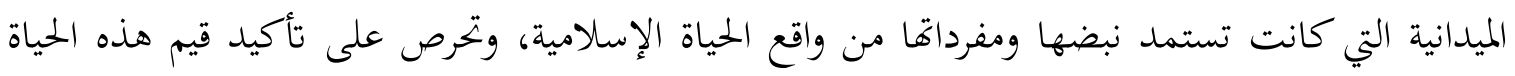
ذات الجذور العقيدية، وهي تصفها وتحكي عنها.

ولم يكن الأمر مسألة رحلة فحسب، بل كانت علماً بدأ بتقديم خدماته لمؤسسات الدولة ولاسيما في بجالي البريد والمال، ثم انفك عنها، وأصبح بتوجيهه المعريف المستقل قديراً على تقديم المزيد من الإضافات

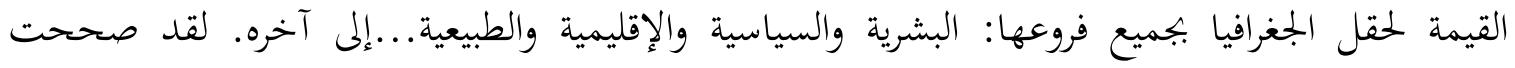
الجغرافيا الإسلامية في كثير من الأحيان معطيات الجغرافيا الإغريقية، بعد قيام الرحالة المسلمين بكشوفهم

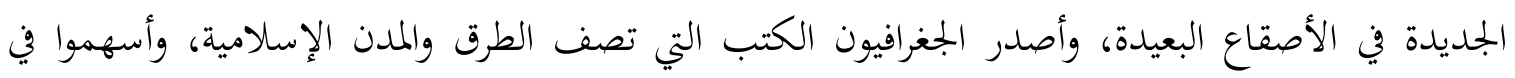
توسيع بجال علم الجغرافيا. ومن أبرز هؤلاء (المقدسي) في كتابه "أحسن التقاسيم في معرفة الأقاليم" الذي لقي

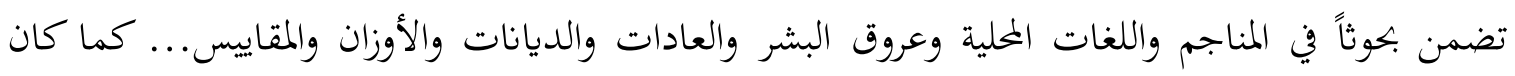
هناك جغرافيون متميزون من أمثال البلخي والأسطخري وابن حوقل. فضلاً عن الإدريسي الذي أشار في الفي

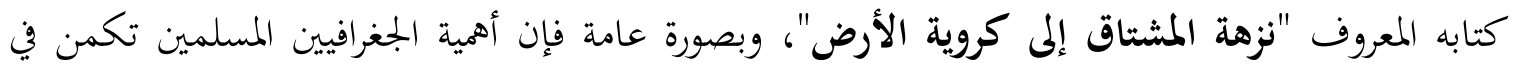
رسمهم الخرائط الجغرافية ووصفهم التفصيلي لمناطق خاصة، أي الجغرافية الإقليمية.

والفلسفة اتخذت في الأساس أداة للجدل من أجل تعزيز الأصول العقيدية للإسلام ومحاججة

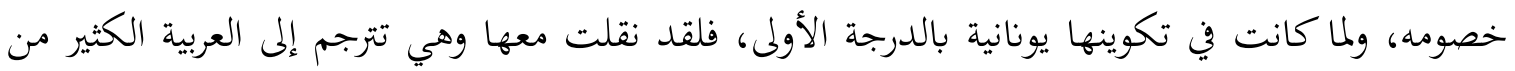


القيم التي قد تتناقض ومبادىء الإسلام، ومن أجل ذلك جرت محاولات واسعة لغربلتها وتنقيتها وجعلها قديرة على أداء مهمتها، متوافقة مع قناعات البيئة التي نقلت إليها.

إن وجود فلاسفة كالكندي والفارابي وابن سينا وابن ماجة وابن رشد، في هذا السياق معروفة، رغم أن

انبهار بعضهم بفلسفة الخصم قد دفعهم إلى تمرير مساحات منها قد لا تتفق وتوجهات الاسلام، ومن ثم كانت تلك الوقفة المعروفة لفيلسوف كبير كالغزالي وكان جدله الشهير في "التهافت" مع ابن رشد، الذي يمثل رغم محاولاته التوفيقية، الابتحاه المذكور بدرجة أو بأخرى.

وبمعنى آخر فإن النشاط الفلسفي، في معظم الأحوال، رغم أنه ليس وليد البيئة الإسلامية، كما هو الحال في علوم أخرى، فإنه قد وظف بشكل من الأشكال، وبغض النظر عن مدى نجاح المحاولة، لخدمة الأهداف الإسلامية.

في علم الاجتماع يبرز ابن خلدون وهو ليس وحده في الميدان، فقد جاء قبله وأعقبه آخرون، لكن مقدمته تظل معلماً بارزاً على قدرة الحياة الإسلامية على إفراز عقل تعليلي نشط كابن خلدون الذي جعل من مقدمته أداة لتحويل النشاط التاريخي إلى فرصة للكشف عن السنن التي تعمل في التاريخ، والتأشير على ما سمي فيما بعد بقوانين الحركة التاريخية، ورغم ما قيل عن هذه المقدمة من قبل بعض الباحثين الغربيين الذين عَدّوها -قسراً- استثناءً ثقافياً للبيئة الإسلامية، فإننا بالرجوع المتأني إلى المقدمة، وإلى حياة الرجل الذي كتبها، سنجدها متجذرة في البيئة الإسلامية، وسنجد صاحبها واحداً من أشد المنتمين للإسلام إخلاصاً لعقيدته وقدرة على فهم دورها في صيرورة المجتمعات. 8

في السياسية نلتقي بتنظيرات كتلك التي قدمها الطرطوشي في "سراج الملوك" والماوردي في "الأحكام السلطانية" ونظام الملك في "سياسة نامه" وغيرهم، تسعى لأن تحاكم مفردات الحياة السياسية، والنظم والمؤسسات الإدارية التي تنبثق عنها، إلى الإسلام، فتقيس به وعليه. وليس المهم ألا تقع في الخطأ، وأن يظل تأويلها سليماً، إنما أن تظل على ولائها للمبادئ الأساسية للشريعة التي كانت، رغم تداعي السلطات واهياراتا، الحكم الفصل في حياة المسلمين، عبر مساحات واسعة من تاريخهم. 8 ع عولجت هذه المسألة بالتفصيل في كتاب للمؤلف بعنوان "ابن خلدون إسلامياً"، المكتب الإسلامي، بيروت - 1983م. 
في الاقتصاد نجد كيف نفذت محاولات جادة لترشيد هذا الجانب أو ذاك من جوانب الحياة الاقتصادية والنشاط المالي، في ضوء المعايير الإسلامية. فأبو يوسف الذي يعهد إليه الخليفة العباسي بمهمة تصنيف كتابه المعروف "الحراج" كان تلميذاً لأبي حنيفة، ونادى في كتابه هذا بضرورة التعامل العادل مع المزارعين وأن تسود قيم العدل الاجتماعي التي أعلنها الإسلام، العلاقة بين الحاكم والمحكوم. والمشكلة الإروائية التي شهدةا بلاد فارس في عهد الطاهريين، والتي تمثلت بمسألة إيجاد نظام لتوزيع مياه الري على المزارعين كافة، عهد بحلها إلى لجنة من الفقهاء عكفت على وضع كتاب يعرف "بالفني" أعان على بتاوز المشكلة بمنظور مستمد من أصول إسلامية لأن الذي قدم الاقتراح هم الفقهاء أنفسهم.

في التربية يكفي أن نرجع إلى معطيات ابن خلدون في "المقدمة"، وإلى الصفحات الأولى من "كشف الظنون" لحاجي خليفة، لكي نرى أن التربية التي تحدثا عنها وقدما إزاءها المقترحات وطرائق العمل هي تربية إسلامية على وجه التحديد، وليس مطلق تربية، وأغما قدرا على تغطية جميع المفردات العملية التربوية من منظور إسلامي أصيل، بل إننا نجد، باستمدادها هذا من أسس التربية الإسلامية، كيف قدرا على تقديم مسائل في هذا الميدان لم تمسها الأنشطة التربوية في العالم إلا في العصر الحديث.

ويكفي أن نتذكر - كذلك - أن "المسجد" والمؤسسة التعبدية عامةً، كانت في أغلب الأحيان مركز العملية التربوية ومنطلقها، فكيف لا تكون المعطيات متشكلة بخصائص المؤسسة التي مارست فيها نشاطها؟ أما الفقه وأصوله، فبوصفهما علمين إسلاميين في الأساس، كعلوم القرآن والحديث، فليس ثمة مبرر للتأشير على إسلمايتهما، لأن الأمر بديهي تماماً.

لكن المرء قد يتذكرها هنا كيف وقف الفقهاء الرواد وقفتهم الصلبة تلك بمواجهة السلطات، وكيف أفم طوردوا واعتقلوا وعذبوا وضربوا بالسياط لرفضهم ما جعلوه خروجاً عن مبادئ الإسلام الذي نذروا أنفسهم له بمعنى آخر أفم عرفوا كيف يوحدون بين الكلمة والسلوك، وكيف يصرون على جعل النشاط العلمي، نشاطاً إسلامياً، ليس بمفرداته فحسب، بل في مناخه وشروطه الأخلاقية.

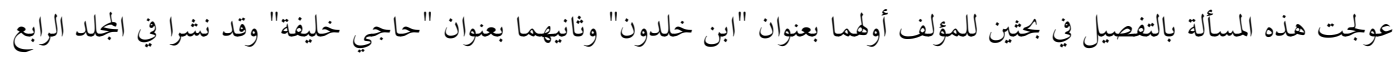
9

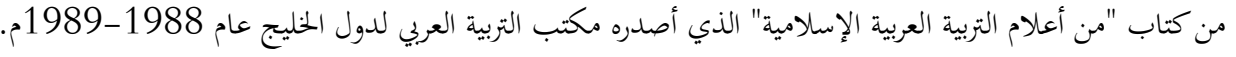


والحديث عن الأدب يطول، وتأثر الحركة الشعرية بالمؤثرات الإسلامية تشكل منذ البدايات، وأخذ يتزايد مع الزمن بمقاييس الكم والنوع، جنباً إلى جنب مع الأنشطة الأدبية واللغوية الأخرى التي انبثق بعضها أساساً عبر التعامل مع كتاب الله... ومضى بعضها الآخر يحمل مؤثرات إسلامية بينة ليس إلى نكراها من سبيل. ولن يستطيع باحث أن يجرد نقاداً كالآمدي والقيرواني وعبد العزيز الجرجاني وابن سلام الجمحي وابن المعتز وقدامة بن جعفر وغيرهم، عن التأثيرات الثقافية للبيئة، والتقاليد الأساسية للعقيدة التي شبوا في ظلالها، رغم أن مساحات ضيقة من معطياتم وأحكامهم تبدو للوهلة الأولى، بعيدة أو منفصلة، عن هذه التأثيرات إنسياقاً منهم وراء المطالب الجمالية الصرفة.

حتى إذا ما بلغنا العلوم الصرفة (فلكاً وفيزياء وكيمياء ورياضيات وهندسة ونبات وحيواناً وأدوية وطباً... إلخ) فإننا نجد كيف أها مارست نشاطها بحرية تامة منحها إياها هذا الدين الذي كان يمثل أقصى ري درجات التناغم والوفاق مع أية محاولة للكشف عن السنن الكونية، ولإزاحة الغطاء عن القوى والطاقات التي سخرها الله سبحانه ابتداء، لعباده القديرين على الكشف والتنقيب. ولقد زادت هذه الحقيقة المؤكدة في كتاب الله وسنة نبيه صلى الله عليه وسلم وفي الممارسات التاريخية بين الحاكم والمحكوم، من تحفيز العلماء على المضي في أنشطتهم إلى المدى الذي بلغوه، فقدموا لحضارتم، وللبشرية كلها، من وراء ذلك، تلك الكشوف الخصبة ذات القيمة العلمية، الصرفة والتطبيقية، والتي أشار إليها واعترف بريادتما وتفوقها الغربيون

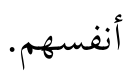

سادساً: سنجد أنفسنا عبر المحور الثالث المشار إليه قبل قليل (من الفقرة الخامسة) (وإلى حد ما المخور الثاني) قبالة ما يمكن أن يغذي أنشطة إسلامية المعرفة والمشروع الحضاري الإسلامي ويمنحهما القدرة على سلى الغناء والتأصيل، ويمنح الأمة قدرات كبيرة في بجابهة تحديات المستقبل والمشاركة العالمية في المصير.

إن انعكاس المبادئ والقيم الاسلامية على مساحات واسعة من الموروث الثقافي منحه خصائصه النوعية المتميزة التي يمكن أن تمثل ليس مبرر استمراره في العالم فحسب، بل قدرته على اقتحام وإغناء شبكة النشاط المعريف للحضارة الراهنة، والقدرة الفعالة على الاسهام المستقبلي فيه. 
إننا بوضع هذه الخصائص في حالة تقابل مع نظيراتها أو أضدادها في الثقافات الأخرى، والغربية الراهنة منها خاصة، فإنها ستمنح الأخيرة فرصاً كثيرة للتعديلات الملحة لهذه الثقافة باستدعاء البدائل الاسلامية ومنحها الفرصة المناسبة للمشاركة.

إن الخصيصة الايمانية للثقافة الإسلامية - على سبيل المثال - تقف بمواجهة التوجه المادي المتزايد للثقافات الأخرى، والتزامها يلجم تفلتها الآخذ بالاتساع من منظومة القيم الخلقية، وواقعيتها تحد من شطط تنظيراتها الفكرية بابتحاه طوباويات الحلم والخيال، وأصالتها تمنح المسار البشري طعماً جديداً متميزاً، وشموليتها، وقدرقا على موازنة الثنائيات ولمها، توقف اندفاع الثقافات الأخرى وميلها إلى هذا الجانب أو ذاك على حسب الجوانب الأخرى التي قد لا تقل أهمية وإلحاحاً. وإنسانيتها تتجاوز بها حواجز العرق واللون والجغرافيا والمذهب... وميزها التحريرية ستنقذ الإنسان في غهاية الأمر من سائر الضغوط والصنميات التي أذلت عنقه وهبطت به درجات عن مستوى بشريته كمخلوق متفرد في هذا العالم، سيّد عليه.

والباحثون الغربيون أنفسهم انتبهوا إلى هذا، وقدموا شهاداتم هذا الخصوص، والتي بتيء كاعتراف حر مدعم بالقناعات العقلية، وموثق بالرؤية المقارنة لما تتضمنه ثقافة الإسلام من قيم وخصائص متميزة وفعالة، يمكن أن تمارس دورها في صياغة حاضر الانسان ومستقبله. 10

سابعاً: في المحصلة النهائية، وكمؤشر عام، فإن علينا ألا نقع في مظنة التسليم بأحد التعميمين التاليين: 1- إن التراث الإسلامي يعبر بكليته عن التصور الإسلامي للكون والحياة والإنسان.

ينظر - على سبيل المثال: مارسيل بوازار: إنسانية الإسلام، ص330-3313، 339، 369، 387-388، 389، 341، 439، 439،

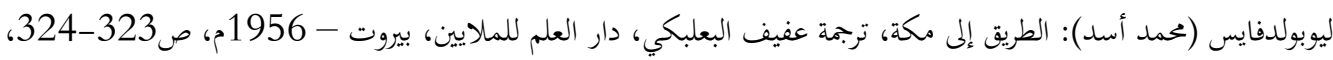

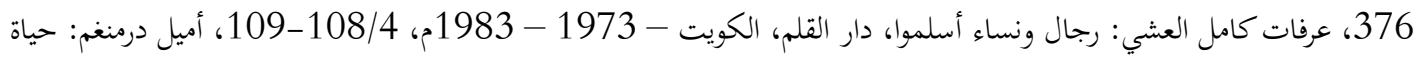

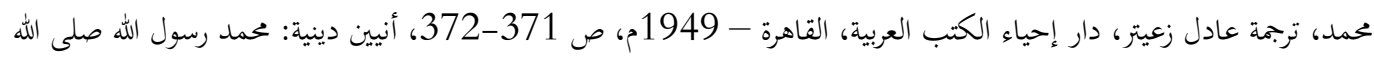

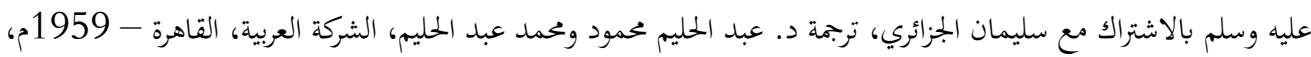

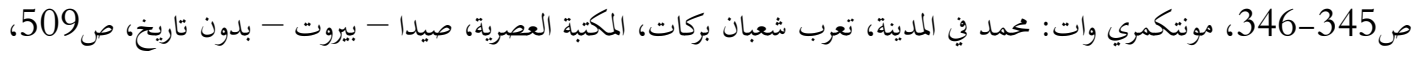

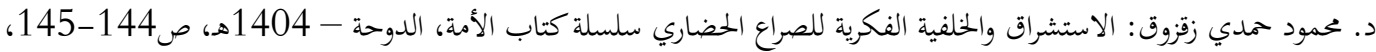

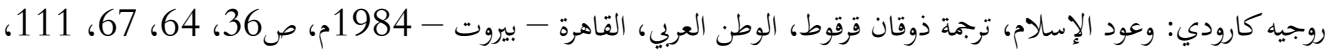

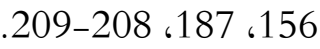


2- إن التراث الإسلامي لا يمثل بالضرورة امتداداً لهذا التصور.

فهذا التراث إنما هو نسيج متداخل الخيوط بين ما هو أصيل وما هو طارئ دخيل.... بين معطيات تشكلت من مقولات القرآن والسنة. وتخلقت في إطاراتما، وبين أنشطة أقحمت إقحاماً في مجرى الفعل الحضاري الاسلامي، بتأثير الدهشة والاعجاب بهذا الجانب أو ذاك من معطيات الغير... أو عن قصدية مسبقة لعناصر غير إسلامية، بالمفهوم غير المحدد للكلمة، لزرع أجسام غريبة في نسيج هذه الحضارة ومحاولة غزوها والتلبيس عليها من الداخل.

وفي كل الأحوال فإن الباحث يجد نفسه قبالة صعوبة بالغة وهو يتعامل مع التراث قبل أن يتبين بوضوح ما هو إسلامي أصيل منها وما هو يوناني أو فارسي أو هندي أو يهودي أو نصراني دخيل. بل إن المعطى الواحد نفسه، في هذا الحقل أو ذاك من حقول المعرفة قد يتضمن المادتين معاً، فهو في بعض جوانبه إسلامي المنطق وفي جانب آخر غير إسلامي، ليس بالضرورة في التفاصيل والجزئيات، ولكن في الخطوط العريضة ومنطلقات التصور الأساسية.

إن ثنائية كهذه تمضي إذاً لكي تعمل عملها باتجاهين، أولمما تشكيل نمطين من المصلات المعرفية متضادين في أسسهما التصورية، وثانيهما جعل المعطى المعريف الواحد يتضمن إشكالية التداخل بين النمطين. وإذا كان هذا يبدو واضحاً فيما اصطلح عليه بالفلسفة الإسلامية بسبب من تأثرها الواضح بالفلسفة اليونانية، وتقبلها الكثير من مقولاتما على مستوى المنهج والموضوع، فإنه قد لا يبدو بهذا القدر من الوضوح في حقول علمية أو إنسانية أخرى.

وفي كل الأحوال، كذلك، فإن محاولات الدراسة والتمحيص ومتابعة طبيعة الارتباط أو الانفصال تقتضي قدراً كبيراً من الإلمام بأسس التصور الإسلامي ومقوماته من جهة، وبمطالب التخصص العلمي بهذا الفرع أو ذاك من فروع المعرفة. ومعنى ذلك أن المحاولة في مجملها تقتضي ملاكاً أو كادراً أو فريقاً متكاملاً يضم جناحيه على المتخصصين (الإسلاميين) في فروع المعرفة كافةً. إذ ليس بمقدور متخصص في الفلسفة مثلاً أن يمارس العمل في حقل التاريخ، وليس بمقدور هذا أن ينفذ المهمة في حقل الفقه والتشريع، كما أنه 
ليس بمقدور الآخرين أن يأتيا بنتائج مقنعة وهما يكلفان بالعمل في حقل اللغويات والآداب والفنون... وهكذا.

قد يلتقي هؤلاء جميعاً في الخطوط العريضة لمنطلقات العمل، هذه الخطوط أو الضوابط (التصورية أو الشرعية) التي لابد أن يحيلوا عليها مفردات الحقول التي يجوسون فيها... لكن، وبعد هذه البداية يمضي كل منهم في طريقة لكي يتعامل مع فرع يختلف في منهجه وتوجهاته ومعطياته ونتائجه وطبية اهتماماته، عن

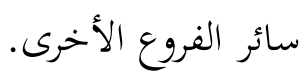

ثمة ضرورة أخرى يتحتم أن نضعها في الحسبان، تلك هي وضع أو تصميم منظومة من المعايير التي يتم بموجبها التعامل مع حشود المعرفة التراثية... ومنظومة كهذه بقدر ما ستمنح النشاط بعداً منهجياً مرسوماً، وليس ضرباً على غير هدى، بقدر ما ستعين العاملين على اختزال الجها والوقت، وصولاً إلى هدفهم المرتجى. ولا يخفى على أحد أن المعارف التراثية ليست سواء في قيمتها "العلمية" وفي قدرتا على التأثير في البنيان المعريف للعصر الذي نعيشه ولمستقبل هذا العصر، أي في تواصلها مع العصر وديمومة فعاليتها في المكان والزمان... كما لا يخفى على أحد أنه بالنسبة إلى المسلمين بالذات فإن هناك سلماً للأولويات يجعل

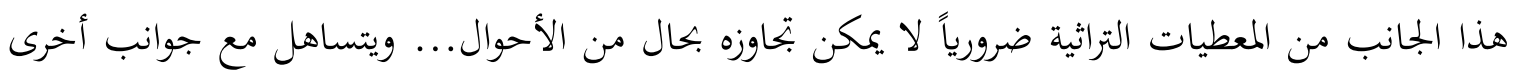
أخذاً ورفضاً... وجوانب ثالثة يبدو أن رفضها أو إهماها في الأقل، يمكن أن يكون ضرورياً.

فإذا وضعنا هذا في الحسبان، فإنه سيوفر علينا الكثير من الطاقات لأنه سيسقط ابتداء ما يمكن تسميته خطأ بحرمة التراث أو قدسيته، الأمر الذي لم يفرض تقبله في إطاره العام وبجميع مفرداته، ومن تََّّ يفرض تمحيصه وفرزه بالكلية وصولاً إلى فك الارتباط بين عناصره الأصيلة ذات الجذور الإسلامية، وتلك التي أقحمت عليها من مصادر خارجية.

لكننا من خلال منظومة الأولويات سنوفر جهداً كهذا إزاء كم كبير من المعطيات التراثية قد لا تكون له، فيما عدا الأهمية التاريخية الساكنة، أي تأثيرات على العصر الذي نعيشه، إن على مستوى البشرية، أو في دائرة الجماعات الاسلامية. 
ولنضرب على ذلك بعض الأمثلة من بين حشود منها لا تعد ولا تحصى. ففي علم الاجتماع أو العمران البشري في المصطلح القديم، يبدو عمل ك "مقدمة ابن خلدون" وسائر الأعمال الأخرى التي حذت حذوه، ضرورية لمطالب البحث في هذا الفرع من فروع المعرفة، ليس على مستوى المسلمين وحدهم، بل في نطاق العالم الذي كانت "المقدمة" عنده كشفاً أساسياً لهذا الحقل المعري المهم، وضعت من خلاله الكثير من مفرداته التي لا تزال الأنشطة المنهجية لمذا العلم تأخذ بها، وتضيف عليها، بكل تأكيد. وفي علم التاريخ فإن المعرفة البشرية عامة لن يكون بمقدورها أن تستكمل تغطيتها المعرفية للتاريخ البشري إن لمُ يُول الاهتمام الكافي لمؤرخ كالطبري مثلاً ولمساحات واسعة من علم التاريخ الاسلامي حماية وكشفاً وتحليلاً وتركيباً... فكيف بالأمة الاسلامية نفسها؟

وما يقال عن الاجتماع والتاريخ يمكن أن يقال - عن التربية والجغرافيا والآداب والفنون... إلخ. فإذا كانت فروع كهذه ضرورة على المستوى العام، فإن ثمة ما هو أشد ضرورة وإلحاحاً بالنسبة إلى المسلمين أنفسهم من مثل التراث القانوني، والفقهي والتشريعي، الذي يمكن بدراسته وتمحيصه وتبويبه، التمهيد لحركة الاجتهاد الإسلامية أن تستأنف من جديد، غير منطلقة من الفراغ، أو قافزة عبر فجوة زمنية متطاولة، وإنما من خلال تواصل زمني مطرد لهذا الفرع الخطير من فروع المعرفة.

صحيح أن الباحثين في هذه العلوم سيجدون في نسيجها مساحات، وربما مساحات واسعة، لم تعد تحمل أية قيمة معرفية أو شرعية، ولنتكر - على سبيل المثال - بعض استنتاجات ابن خلدون الناقصة أو الخاطئة، على مستوى علم الاجتماع، وحشود الأكاذيب والتحزبات والميول والأهواء على مستوى التاريخ، وسيول الإسرائيليات على مستوى علوم القرآن، والحلول الفقهية لمشاكل ومتغيرات عفا عليها الزمن على

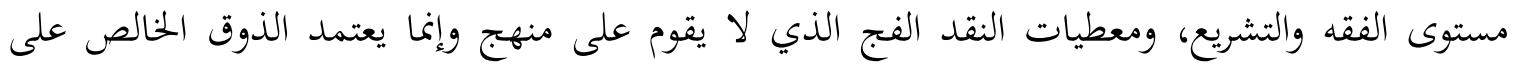
مستوى الآداب... إلخ. ولكن هذا كله لن يسقط حسبان هذه المعارف على خط الضرورات البشرية والشرعية... كل ما هنالك أنه سيتيح للباحث فرصة لإسقاط المساحات غير المجدية في نسيج هذه المعطيات، الأمر الذي قد يخفف عن كاهله جانباً ليس بهين من عبء التمحيص الذي أنيط به. 
لكن في مقابل هذا كله، أنماط من المعارف قد لا تمثل التضحية بها أو تجاوز فرزها وتمحيصها أو

تعليقها زمنياً في الأقل، خسارة كبيرة على مستوى المعرفة البشرية أو الضرورات العقيدية والتشريعية، وأرجو ألا أكون مخطئاً أو مبالغاً إذا ضربت على ذلك مثلاً بالفلاسفة ابن سينا، والكندي، والفارابي... وأمثالهم، والجدليات الفرقية، وأقسام واسعة من علم الكلام، والكثير من النظريات الفجة الناقصة في ججالات العلوم الصرفة والتطبيقية ولاسيما علوم الطبيعة والفلك والحياة والنفس... إلخ.

والمهم أن وضع معارف كهذه في أسفل المنظومة سيخفف العبء عن عاتق العاملين في تمحيص التراث ويمكنهم من تقديم الأهم على المهم على الأقل أهمية، ومن تََّّ سيوفر عليهم الكثير من الجها والوقت اللازمين لإنجاز مهمة ملحة كهذه تعد واحدة من أكثر الضرورات أهمية في مشروع أسلمة المعرفة لأها بمثابة تحذير لعمل في الأصول التصورية والحضارية والتاريخية للأمة الإسلامية، وبحاوز لمجازفة الانطلاق من نقطة الصفر أو الحركة في الفراغ.

لقد أصبح التراث الإسلامي في العقدين الأخيرين خاصة، ساحة فتوح يصول فيها ويجول مفكرون لا يملكون قدراً كافياً من فهم أسس التصور الإسلامي ومقوماته، بل هم في كثير من الأحيان في خصام مع هذه الأسس والمقومات، الأمر الذي كان يقودهم إلى توظيف هذا التراث لتأكيد استتاجاهم باعتماد منهج منقوص لا يستقرئ هذا التراث لاستخلاص مؤشراته الأساسية في هذه الدائرة أو تلك من دوائر معطياته المعرفية الخصبة المتشابكة، ولكنه يمارس علمية انتقاء كيفي، تستبعد - بحكم التحزب والهوى - الكثير من عناصره الأصيلة، ولا تستبقي سوى الشواهد التي تؤكد هذا الاستنتاج المحدود أو ذاك.

ولا ريب في أن الاهتمام الجاد الذي ستوليه أنشطة أسلمة المعرفة لدائرة التراث، والمنهج الدقيق الأصيل الذي ستعتمده، والتصور "العلمي" الذي ستنطلق منه في فهم مفردات هذا التراث وتحليلها وتمحيصها، فيما يجعلها أثر قدرة على استيطان جوهر معطياته وملامسة حقيقتها إن هذا كله سيبرر الجهود المضنية التي ستأخذ المحاولة نفسها بها، لأنه سيقدم ثماره التي نضجت على مهل، وفي بيئها الطبيعية، ليس لمشروع أسلمة المعرفة فحسب، بل لكل المعنيين بالتراث أكاديمياً وعقدياً، وسيقطع الطريق على سائر المحاولات 
المبتسرة الناقصة، المرسومة سلفاً، تلك التي تسعى إلى توظيف المعطيات السخية لهذا التراث بالحق والباطل، لتأكيد قناعاتما المتقاطعة - أساساً مع بداهات التصور الاسلامي. 